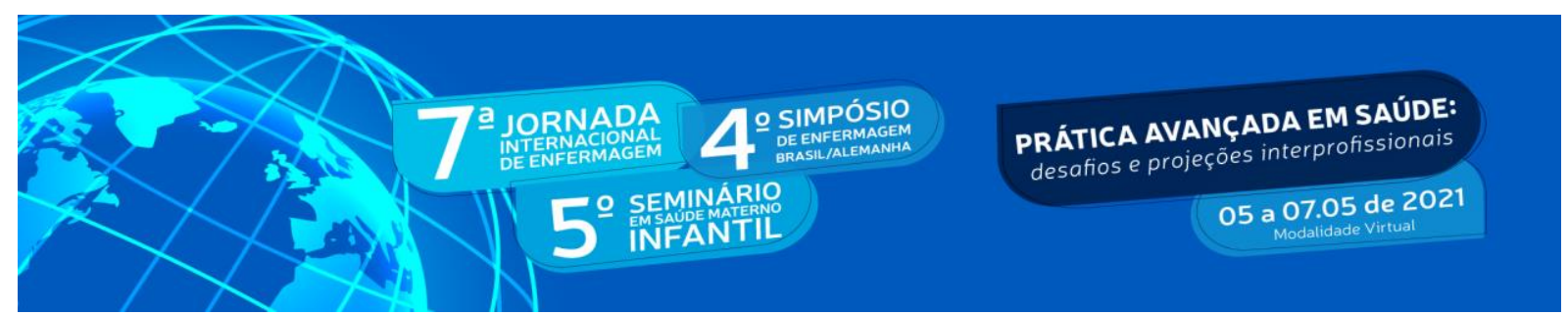

DOI: http://doi.org/10.48195/jie2021-004

\title{
SAÚDE MENTAL DE ESTUDANTES DE ENFERMAGEM EM TEMPOS DE PANDEMIA ${ }^{1}$
}

\section{Adilson Batista da Silva²; Gabriélly Alves Severo'; Manoelle Miollo Vieiraª Jucimara Montagner Michelon; ${ }^{3}$ Dirce Stein Backes ${ }^{4}$}

\begin{abstract}
RESUMO
Trata-se de um relato de experiência para traçar o planejamento e possibilitar programa de apoio à luz da Teoria da Adaptação de Callista Roy onde será avaliado e ampliado a percepção teórica e prática de um determinado fenômeno social, com vistas ao desenvolvimento crítico-reflexivo do profissional de Enfermagem. Realizado por meio de uma enquete informal com estudantes de um Curso de Enfermagem, para identificar os efeitos da pandemia do COVID-19 sobre a saúde mental. Obtiveramse os seguintes resultados o qual contabilizou os índices de ansiedade em $92,9 \%$, em seguida com 82,1\% desânimo, estresse com $82,1 \%$ e desmotivação com $71,4 \%$ das respostas, estes índices de saúde mental são fatores prejudiciais ao aprendizado. Deste modo pode-se concluir que a teoria da adaptação auxilia os discentes a uma readaptação com a nova demanda de estudos no período pandêmico.
\end{abstract}

Palavras-chave: Saúde mental, acadêmicos, enfermagem, pandemia.

\section{ABSTRACT}

This is an experience report to outline the planning and enable a support program in the light of Callista Roy's Theory of Adaptation where the theoretical and practical perception of a given social phenomenon will be evaluated and expanded, with a view to the critical-reflective development of the Nursing professional. Conducted through an informal survey with students of a Nursing Course, to identify the effects of the COVID-19 pandemic on mental health. The following results were obtained which accounted for the anxiety indices in $92.9 \%$, then with $82.1 \%$ discouragement, stress with $82.1 \%$ and demotivation with $71.4 \%$ of the answers, these mental health indices are factors detrimental to learning. Thus, it can be concluded that the theory of adaptation helps students to readapt with the new demand for studies in the pandemic period.

Key Words: Mental health, academics, nursing, pandemic.

\section{INTRODUÇÃO}

Segundo a Organização Mundial de Saúde (OMS) a COVID-19 é uma doença infecciosa, causada por uma nova cepa de coronavírus (SARS-Cov-2), que apresenta um espectro clínico variando de infecções assintomáticas a quadros graves na. Sua transmissão

\footnotetext{
${ }^{1}$ Trabalho relacionado à disciplina de Fundamentos Teórico Filosófico da Enfermagem do Curso de Enfermagem da Universidade Franciscana - UFN.

${ }^{2}$ Estudantes do Curso de Enfermagem da Universidade Franciscana - UFN. E-mail: gabriellyalvessevero@gmail.com;manoelle2904@gmail.com:adilsonbs82@gmail.com

${ }^{3}$ Enfermeira Obstetra. Mestranda em Saúde Materno-Infantil acordo CAPES/COFEN-UFN. E-mail : enfer:jucimara@gmail.com

${ }^{4}$ Doutora em Enfermagem. Professora do Curso de Enfermagem da UFN. Orientadora do Trabalho
} 


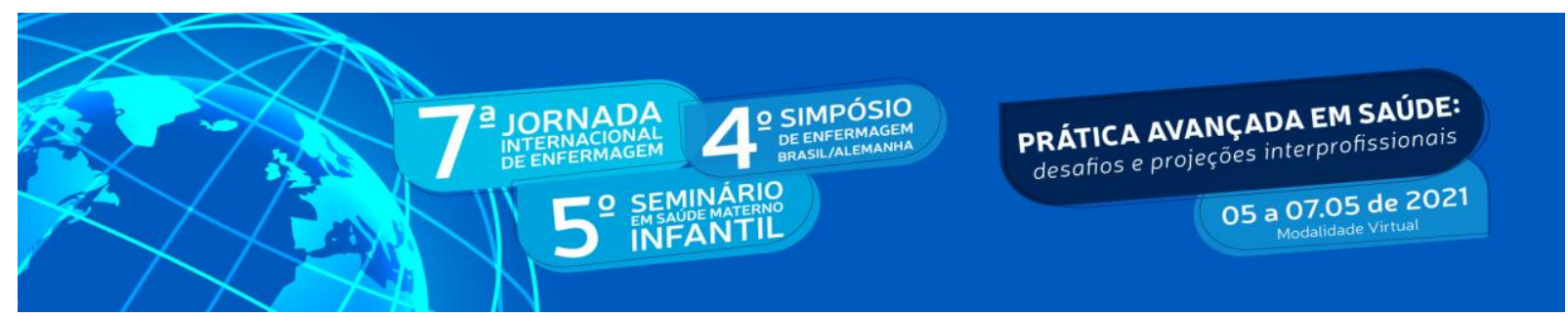

ISSN: 2318-0234

ocorre de uma pessoa doente para outra, através do toque, do aperto de mão contaminadas, gotículas de saliva, espirro, tosse, catarro, objetos ou superfícies contaminadas, como celulares, mesas, talheres, maçanetas, brinquedos, teclados de computador, entre outros.

Pensando na contenção da pandemia, em 13 de março de 2020, o Ministério da Saúde regulamentou critérios de isolamento/afastamento social e quarentena para serem aplicados pelas autoridades sanitárias em pacientes com suspeita ou confirmação de infecção por coronavírus, tendo decretado estado de calamidade pública como estratégias de saúde pública. (BRASIL, 2020).

Com a pandemia já instalada, o distanciamento social é um importante aliado para tentar reduzir o índice de pessoas contaminadas pelo vírus. Diante desta realidade, é necessário pensar na saúde mental das pessoas submetidas ao isolamento social neste período. Com isso, o presente estudo foca em realizar uma análise de dados sobre a saúde mental dos acadêmicos de enfermagem e traçar estratégias que buscam amenizar o efeito, diante da luz da teoria da adaptação.

Diante do risco representado pelas aglomerações, comuns na educação presencial, autoridades decretaram medidas bastante rígidas, começando por férias e suspensão temporária das aulas. Logo, durante esse momento atípico, as instituições de ensino buscaram alternativas para melhor adaptação em meio a pandemia, como tecnologias e ensino à distância, se tornaram aliados para dar continuidade ao ano letivo. (BRASIL, 2020)

A adaptação com o novo modelo de aulas, resultou em algumas fragilidades no aprendizado dos acadêmicos, dentre elas a apreensão e o medo de ser infectado pelo novo coronavírus. Logo, este período pandêmico vivenciado expôs a fragilidade e os riscos à saúde mental de qualquer pessoa, o exemplo que o presente artigo traz para demonstrar o impacto causado aos estudantes de enfermagem é uma enquete informal realizada com os acadêmicos para analisar a saúde mental dos mesmos durante a pandemia (MAIA e DIAS, 2020).

Concomitante a isto, Pereira (2020) ressalta que a saúde mental é considerada um estado de bem estar, onde o ser humano poderá desenvolver vários tipos de emoções, incluindo o stress normal da vida. Para tanto, o bem estar mental é considerado primordial para o indivíduo desenvolver as atividades do cotidiano, visto que, pode influenciar positivamente ou negativamente na rotina. 


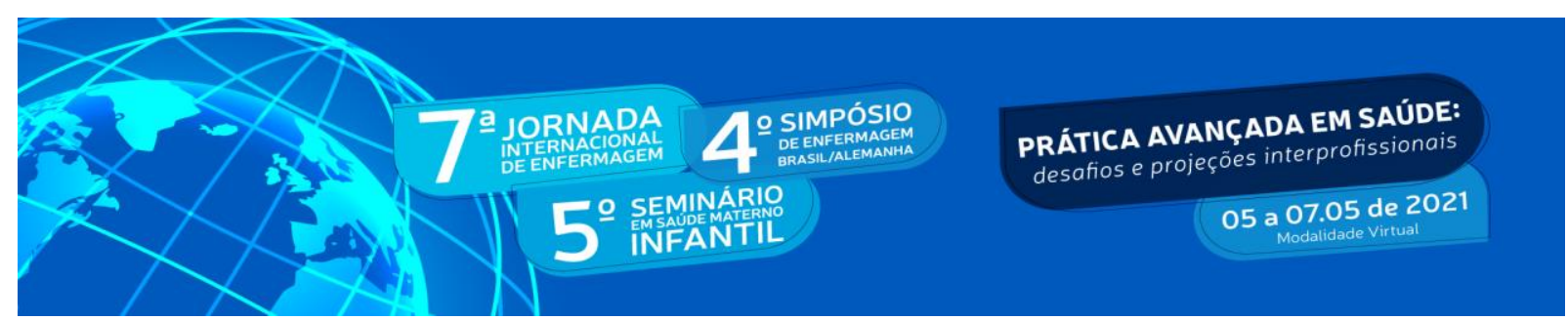

Para Callista Roy, autora da Teoria da Adaptação, o ser humano é visto como ser adaptável a estímulos ambientais, em situações inevitáveis como a morte, a doença, a infelicidade ou o estresse. Mas há uma capacidade de lidar com estas vivências e, com auxílio da enfermagem adaptar-se a cada realidade. A teoria é um instrumento valioso para a enfermagem, guiando-o para a coleta de dados, planejamento e implementação da adaptação do paciente (COELHO, 2011).

Para reconhecer os efeitos da pandemia sobre a saúde mental, os dados da enquete serviram de diagnóstico para traçar o planejamento e possibilitar estratégias de apoio ao enfrentamento à nova realidade, à luz da Teoria da Adaptação.

\section{OBJETIVO}

O principal objetivo desta avaliação é ampliar a percepção teórica e prática de um determinado fenômeno social, com vistas ao desenvolvimento crítico-reflexivo do profissional de Enfermagem.

\section{METODOLOGIA}

Trata-se de um relato de experiência realizado a partir de uma enquete informal com 28 estudantes de Enfermagem. O estudo foi desenvolvido com base nas cinco fases do Processo de Enfermagem: Histórico, Diagnóstico, Planejamento, Implementação e Avaliação de Enfermagem, fundamentado na Teoria da Adaptação escrita por Callista Roy, 1970, onde diz que o ser humano é formado teoricamente em "pessoas, ambiente e saúde" sendo este capaz de lidar e adaptar-se entre as situações.

Deste modo, foi elaborada uma enquete online no aplicativo de nome Google Forms, sendo intitulada como "Saúde mental de acadêmicos de enfermagem durante o período pandêmico". Nela conteve 3 questões objetivas e 2 questões de múltipla escolha, sendo de caráter voluntário e anônimo por meio de um formulário digital, exigindo apenas idade, gênero e semestre que está cursando como identificação.

As questões de múltipla escolha abordaram especificamente dos sentimentos mais presentes durante o período pandêmico, já as dissertativas, focam na análise desses sentimentos em relação as aulas remotas e no seu desempenho enquanto acadêmico. As perguntas foram enviadas através dos grupos de turma de cada semestre que existiam no aplicativo multiplataforma de mensagens instantâneas e chamadas de voz, de nome WhatsApp. 


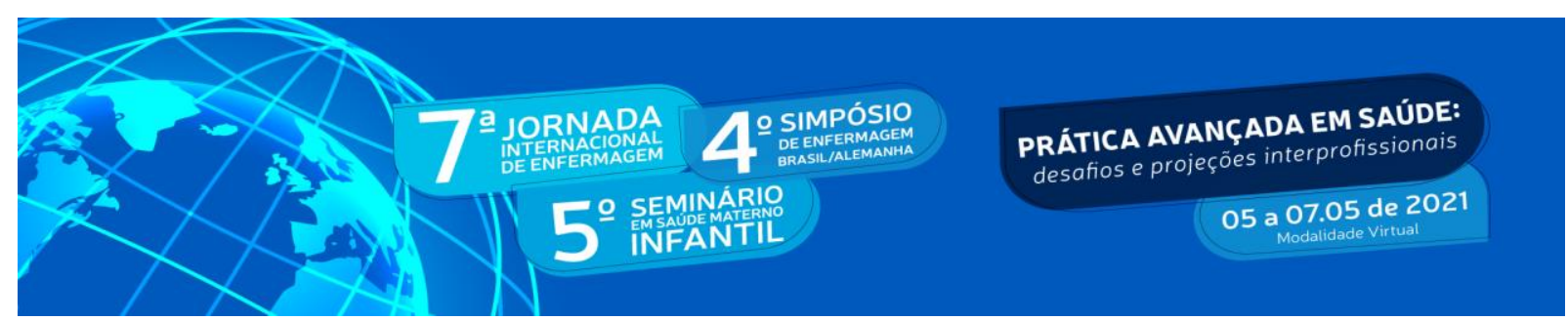

O presente estudo, está vinculado à disciplina de "Fundamentos Teórico-Filosóficos de Enfermagem" do Curso de Enfermagem da Universidade Franciscana, desenvolvida no $4^{\circ}$ semestre de Enfermagem, neste caso no segundo semestre de 2020. O principal objetivo desta avaliação é ampliar a percepção teórica e prática de um determinado fenômeno social, com vistas ao desenvolvimento crítico-reflexivo do profissional de Enfermagem.

\section{RESULTADOS E DISCUSSÃO}

\section{Histórico e Diagnóstico de Enfermagem:}

Apresenta-se, a seguir, a sistematização de assistência de Enfermagem, fundamentada na Teoria da Adaptação. Com base na vivência atual referente a COVID-19, percebeu-se a necessidade de atentar para a Saúde Mental da população, em especial acadêmicos de enfermagem, pois segundo LIMA (2020), esses discentes são mais suscetíveis a desenvolver problemas psicológicos e uso de válvulas de escape, dentre elas, destacamos o alcoolismo. Acadêmicos de enfermagem estão a lidar constantemente com a dor de seus pacientes, as emoções entre ganhos e perdas, e agora acrescenta-se o fator em lidar com o medo do vírus, a frustração com seu desenvolvimento acadêmico e a solidão.

$\mathrm{Na}$ análise dos dados, as questões de múltipla escolha tratam especificamente dos sentimentos, e as perguntas dissertativas do desempenho enquanto acadêmicos, posteriormente, as perguntas foram enviadas através dos grupos de turma de cada semestre. Logo, após enviar link da enquete via WhatsApp, foi analisado os resultados, o qual contabilizou os índices de ansiedade em 92,9\%, em seguida com 82,1\% desânimo, estresse com 82,1\% e desmotivação com $71,4 \%$ das respostas (FIGURA 1).

A ansiedade reflete no discente em dificuldade de concentração, redução da memória, inquietação, dores de cabeça e musculares, tonturas, dificuldades para dormir. Interferindo negativamente no desempenho acadêmico a ansiedade afeta o córtex pré-frontal e o hipocampo, regiões que se relacionam ao aprendizado e memória (REIS et.al, 2017). Presente em todas as situações, o estresse exige capacidade de adaptação, domínio físico, cognitivo, emocional e comportamental, prejudicial a atenção e concentração, demora na resposta de estímulos, deterioração da memória repercutindo no processo ensino aprendizagem do acadêmico (MONDARDO, 2005). 


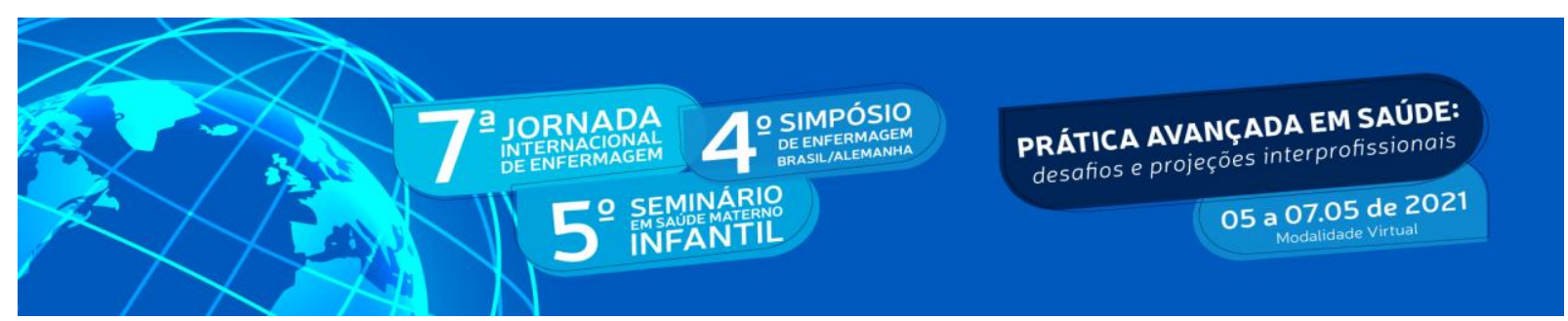

Figura 1: Análise dos sentimentos mais presentes durante a pandemia

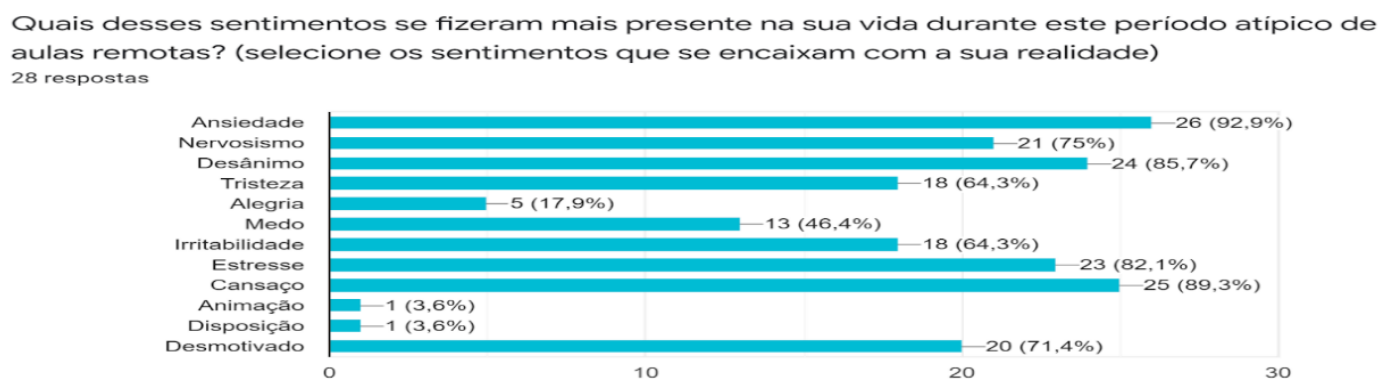

Em consequência destes sentimentos, nota-se que os acadêmicos não obtiveram um desempenho desejado, sendo 24,1\% marcando a resposta como ruim. Em contrapartida, houve 48,3\% das respostas tidas como desempenho bom. Segundo COELHO et.al (2020) entende-se que o isolamento prejudicou a interação com as atividades diárias, trouxe frustrações com eventos cancelados e distanciamento de familiares, desfazendo a rotina de muitos e expondoos ao estresse. Assim, despertou o desânimo com suas atividades, que no caso apresentado da enquete, pode ter sido um grande aliado para o baixo desempenho dos acadêmicos (FIGURA 2).

Figura 2: Resultados do desempenho acadêmico em aulas remotas

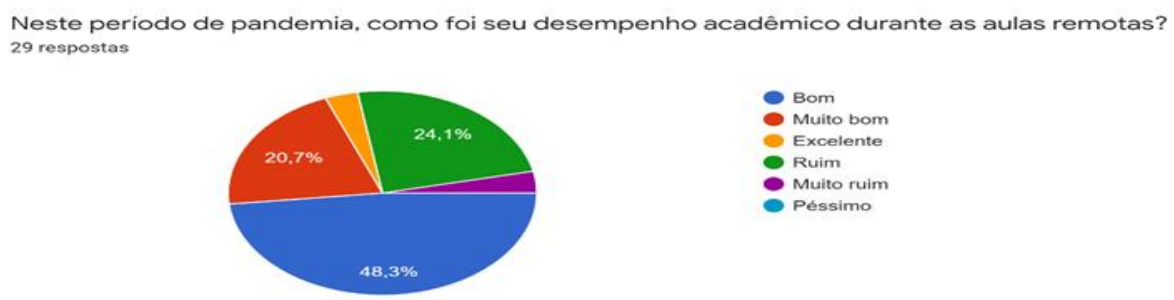

De acordo com LIMA (2020), os acadêmicos estão mais predispostos ao consumo exagerado de álcool e drogas, em consequência de suas frustrações. No resultado da enquete 3 se questionou "Quais métodos você utilizou para amenizar sentimentos ruins durante o isolamento social?" na Figura 3, percebe-se que os acadêmicos optaram por atividades físicas com $64 \%$ das respostas, $32 \%$ para atividades culturais e $24 \%$ ajuda psicológica. Concomitante a isto relata que terapias alternativas como espiritualidade e religiosidade são fatores que auxiliam no enfrentamento da pandemia, associados ao bem-estar psicológico.

Figura 3: Métodos utilizados para amenizar os sentimentos ruins. 


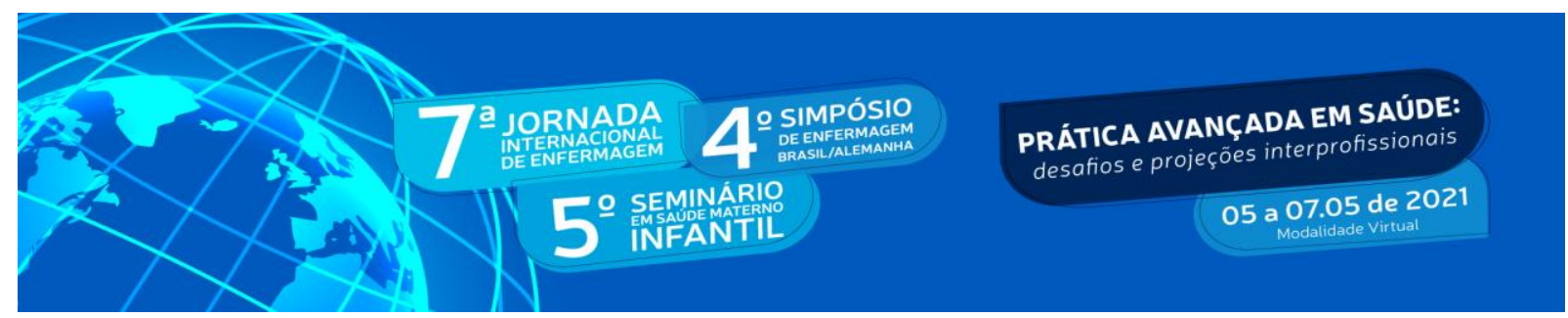

ISSN: 2318-0234

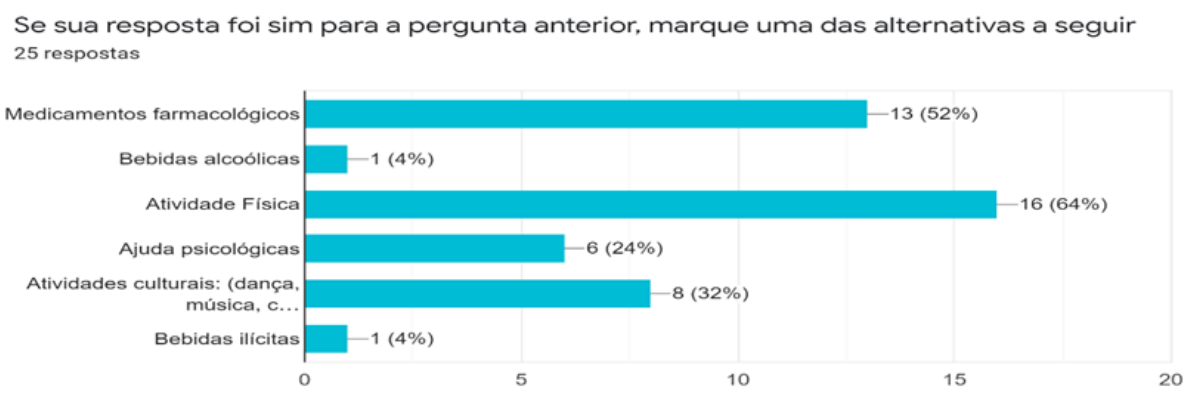

Planejamento, Implementação e Avaliação de Enfermagem.

Analisando os resultados da enquete, observou-se com níveis mais altos: ansiedade, estresse, desânimo, cansaço e desmotivação. Neste contexto, foi acrescentado a seguir, dois infográficos que serviram de apoio no processo de readaptação acadêmica face à pandemia da Covid-19, à luz da Teoria da Adaptação.

Infográfico 1: Trata-se de informações que buscam amenizar os sentimentos mais relevantes que apareceram na enquete sendo eles: ansiedade, estresse, desânimo, cansaço e desmotivação a luz da teoria da adaptação. Segundo Aurélio (2020), a prática de exercício físico durante a pandemia contribui na diminuição de casos de ansiedade e depressão durante este período. Sendo considerado um método não farmacológico eficaz e acessível. A internet está sendo um grande aliado para a promoção de atividade física, visto que já existem sites e aplicativos de smartphones disponíveis para pessoas que buscam formas diferentes de se manter ativos na pandemia. Os aplicativos utilizam de videoaulas com os exercícios práticos a serem realizados em casa, e alertam as pessoas para evitar realizar atividade física se apresentar sintomas como febre alta e dificuldade de respirar.

Outra maneira que diminui os índices caracterizados na enquete, como "sentimentos ruins" é o diálogo entre professor e aluno, o qual contribuirá na diminuição dos índices de desânimo e desmotivação, visto que os professores podem acompanhar seus alunos através do Ambiente Virtual de Aprendizagem (AVA), onde contém várias informações auxiliando o mediador da disciplina para acompanhar o aluno, através dos fóruns e chat ou, dos relatórios como frequência, entrega de atividades dentre outros. É possível que o professor identifique os alunos que se encontram mais desanimados e desmotivados para a realização de tarefa e contribuição em fóruns e chat (SANTOS,2016). 


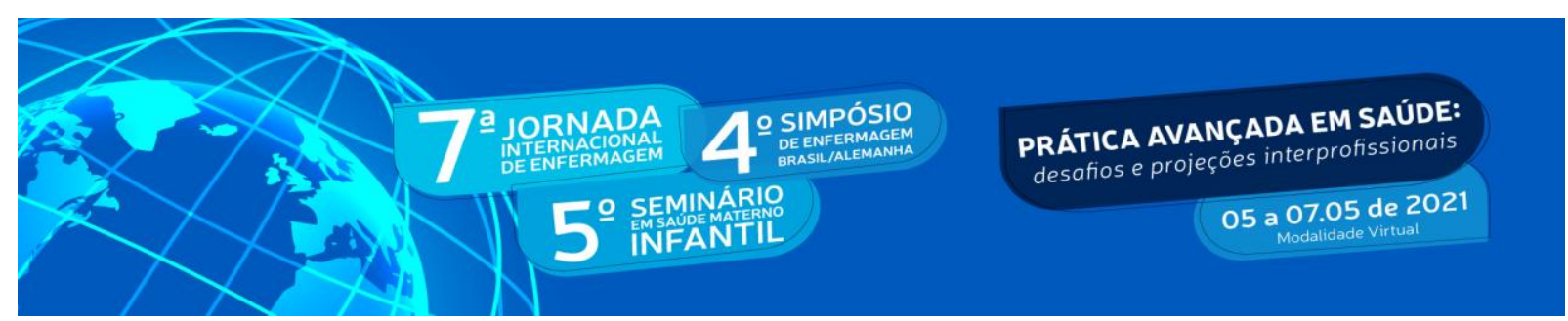

ISSN: 2318-0234

Se faz necessário potencializar e incentivar uma comunicação informal entre alunos e professores contribuindo um melhor enfrentamento ao desânimo durante as aulas via plataforma online. Outro ponto a ser amenizado, é o estresse, que teve o índice de $82,1 \%$ na enquete, sendo necessário um olhar diferenciado e desenvolver ações para contribuir com a diminuição deste dado. Para este fim, novamente as ferramentas tecnológicas são consideradas uma grande aliada, pois segundo Dos Santos, (2020) aplicativos de meditação e relaxamento podem contribuir em situações de ansiedade estresse.

Infográfico 2: Trata-se de orientações para a readaptação acadêmica, com o novo método de ensino remoto instalado durante a pandemia da Covid 19, a luz da teoria da adaptação de Callista Roy (1970). Com a ajuda da teoria entende-se que há possibilidade de adaptação a essa nova modalidade, as pessoas são seres biopsicossociais, sendo submetidas a diversas mudanças no meio que vivem. Tal adaptação, é essencial para que haja uma interação positiva com o meio. Contudo, todos os seres têm condições/ elementos adaptativos, que se tornam pontos positivos para a adaptação das aulas remotas (VEIGA, 2020).

A teoria de Calista Roy, traz as diversas maneiras que encontramos para se adaptar a situações, sendo caracterizadas por estímulos externos e internos que o ambiente proporciona. A teoria em questão, traz quatro modos de estímulos para a adaptação, sendo eles autoconceito, desempenho de papel, interdependência e o modo fisiológico. Logo, o modo fisiológico aborda os estímulos necessários para os seres vivos, sendo eles, a alimentação, oxigenação, repouso e atividade (VEIGA, 2020).

No critério alimentação, vale trazer reflexões as quais em Home Office há maior disponibilidade de tempo e acesso aos alimentos, proporcionando maior probabilidade de descontar sua insatisfação na alimentação. Cita-se por exemplo o carboidrato, que estimula a produção de serotonina, resultando em perda na qualidade nutricional (VEIGA,2020). Portanto, se faz necessário estimular os estudantes a terem uma alimentação balanceada, de acordo com a sua realidade, aconselhando consumir porções pequenas, em intervalos menores entre as refeições.

O segundo modo de adaptação é autoconceito. dividido em duas etapas, a primeira etapa é conhecida como eu físico, e a segunda como eu pessoal. A primeira etapa é relacionada a percepção do indivíduo às suas características físicas, a segunda etapa se baseia em três aspectos 


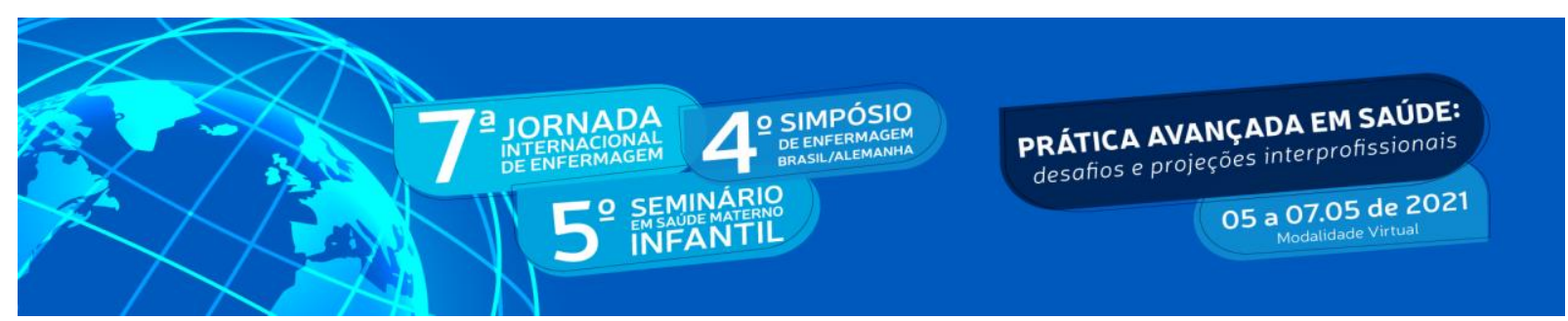

ISSN: 2318-0234

sendo ele, auto consistência (capacidade de enfrentar o desequilíbrio), o auto ideal (o que a pessoa espera de si próprio e do mundo) e, o espiritual-ético-moral (crenças e valores que a pessoa acredita) (VEIGA,2020).

Levando essa etapa do autoconceito para realidade acadêmica em aulas remotas é possível observar que em suas residências os estudantes expressam-se de diferentes maneiras do que seria na modalidade presencial, com autonomia da gestão do seu tempo resultando em seus estudos, e, em qual lugar estudar. A organização do ambiente de estudo contribui no desempenho das atividades acadêmicas, ambientes calmos e tranquilos permitindo assim uma maior concentração. Entender a si mesmo contribuirá nas decisões das atividades em meio remoto (VEIGA, 2020).

O terceiro modo é o desempenho de papel que atribui as funções sociais do indivíduo, em decorrência do isolamento social, tornou-se difícil entender o papel do indivíduo na sociedade, entretanto podemos observar o modelo de aprendizagem de aulas remotas, como sendo uma sociedade online, havendo o papel dos alunos e professores, onde juntos constroem uma relação social, logo sendo de profunda importância uma rotina de diálogo entre eles (VEIGA, 2020).

O modo Independente foca na interação interpessoal e interação sentimental, sendo preocupante na pandemia, devido isolamento social muitas pessoas deixam de interagir com familiares e amigos para tentar diminuir o avanço do contágio, proporcionando então um déficit nas relações interpessoais (VEIGA, 2020). Assim concluímos que as etapas da teoria da adaptação conseguem auxiliar para que possamos nortear os acadêmicos para uma readaptação a modalidade remota.

\section{CONCLUSÃO}

Contudo, neste trabalho foi possível demonstrar os índices de sentimentos caracterizados como "sentimentos ruins" e o desempenho acadêmico durante esse período pandêmico com, em Discentes de enfermagem do $4^{\circ}$ e $5^{\circ}$ semestre de uma universidade, proporcionando também estratégias para estimular a adaptação dos discentes frente ao novo normal. Concluímos o presente estudo afirmando atingir o objetivo do trabalho, a teoria em questão de Callista Roy 1970 foi fundamental para suprir as necessidades dos acadêmicos em 


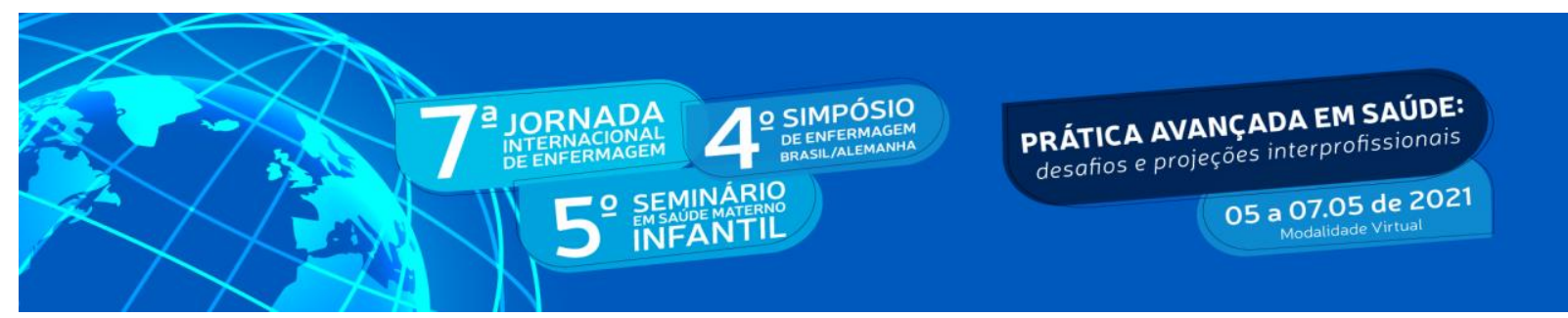

ISSN: 2318-0234

questão, bem como a teoria da adaptação comprova que as pessoas são capazes de se adaptar às mudanças da vida.

\section{Infográfico 1}

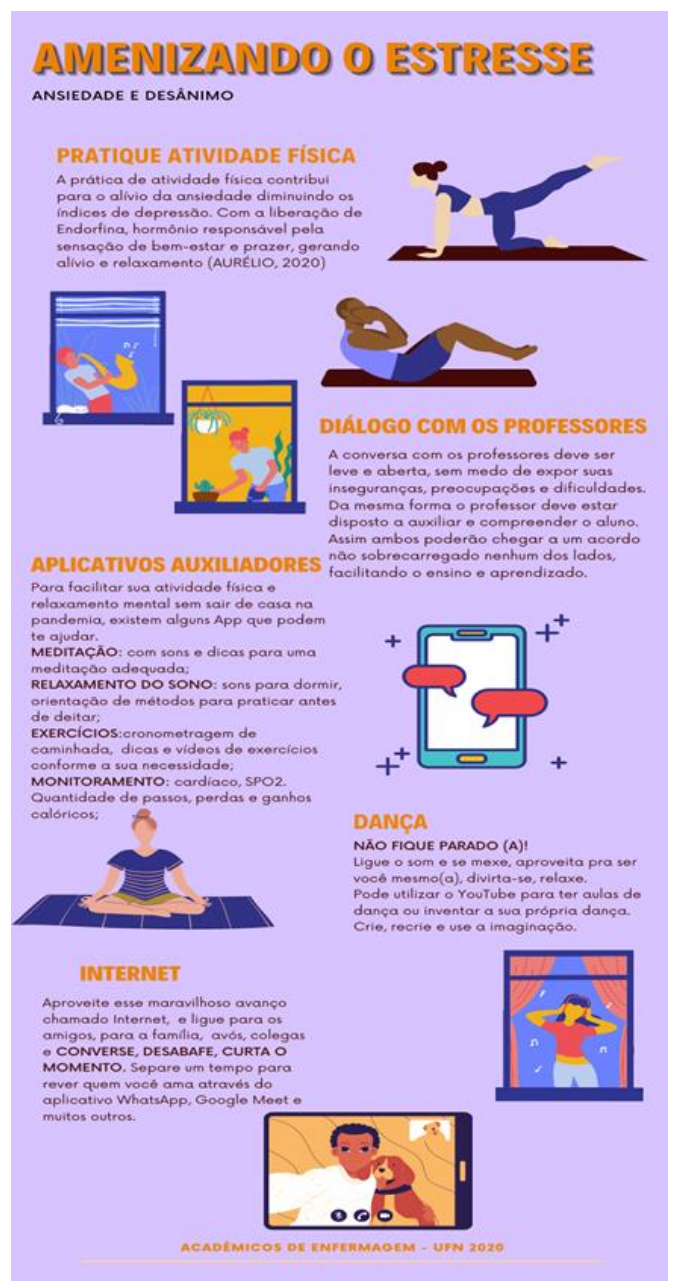

\section{Infográfico 2}

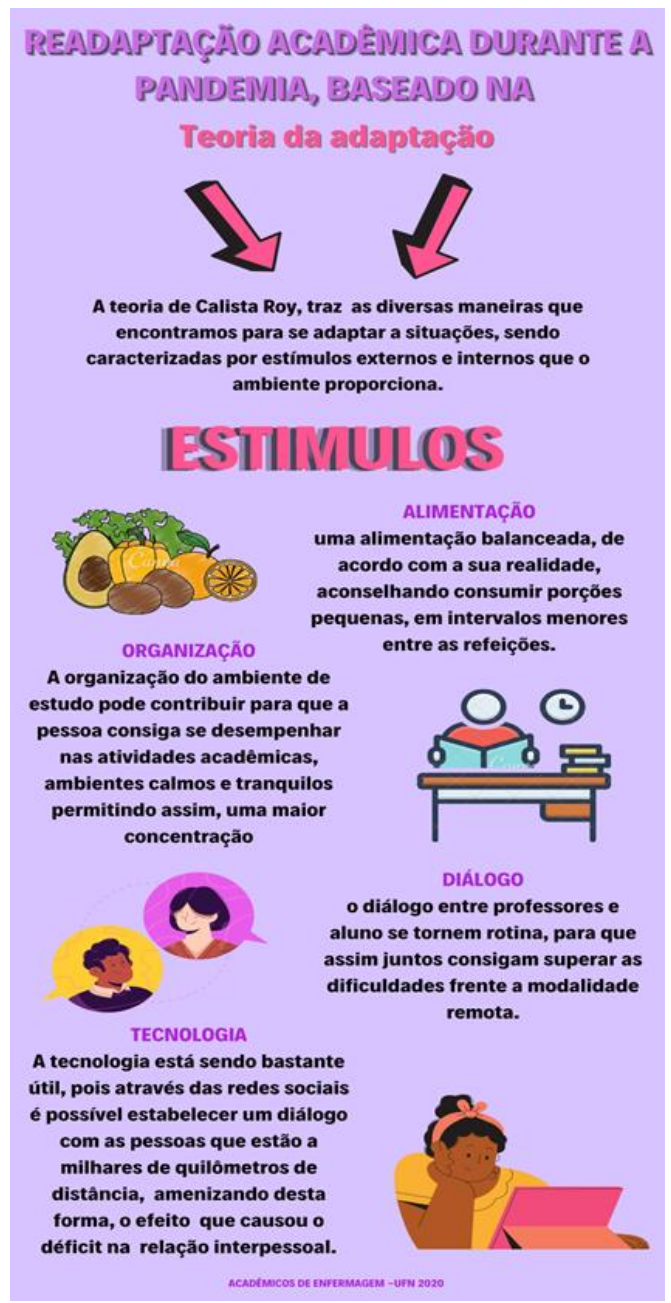

\section{REFERÊECIA}

AURÉLIO, S. da S. Atividade física no combate a incidência de depressão e ansiedade na pandemia do covid-19: Uma revisão de literatura. Trabalho Conclusão de curso (Educação Física Bacharelado), Tubarão, 2020. Disponível em:

https://repositorio.animaeducacao.com.br/handle/ANIMA/12635

COELHO, A.P.S. Saúde mental e qualidade do sono entre estudantes universitários em tempos de pandemia da COVID-19: Experiência de um programa de assistência estudantil. Research, Society and Development, v. 9, n.9, 2020. Disponível em: https://rsdjournal.org/index.php/rsd/article/view/8074/7227 


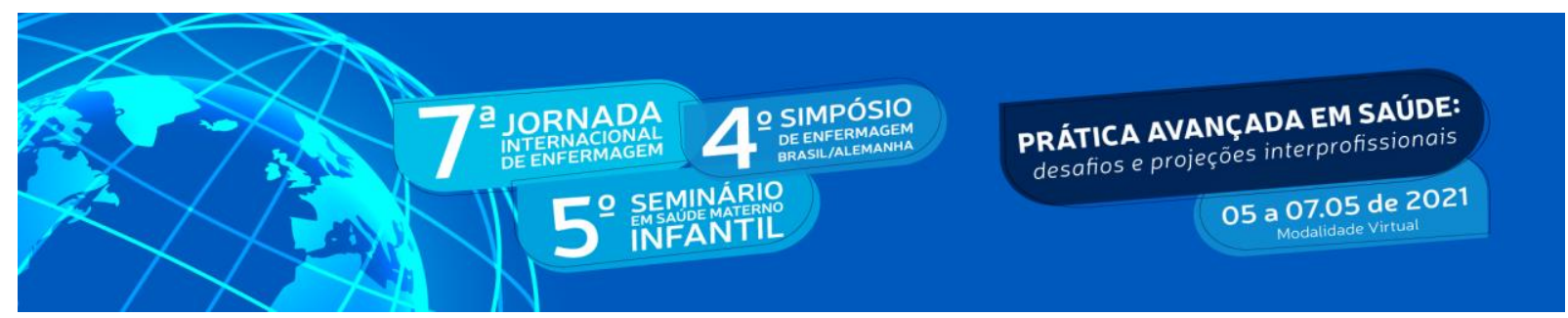

ISSN: 2318-0234

COELHO, S.M.S; MENDES, I.M.D.M. Da pesquisa à prática de enfermagem aplicando o Modelo de Adaptação de Roy. Esc Anna Nery (impr.) v.15 n.4. p. 845-850, 2011. Disponível em: https://www.scielo.br/pdf/ean/v15n4/a26v15n4.pdf

DOS SANTOS, G. B. et al. Estratégias para redução do estresse ocupacional em trabalhadores da saúde durante a pandemia por COVID-19: uma revisão da literatura.

Research, Society and Development, v. 9, n. 11, 2020.

LIMA, C.S. Saúde mental, uso de substâncias e religiosidade dos estudantes do curso de graduação em enfermagem frente a Pandemia da covid-19. 2020. Trabalho Conclusão de Curso (Bacharelado e Licenciatura em Enfermagem) - Universidade Federal de Uberlândia, Minas Gerais, 2020. Disponível em: http://repositorio.ufu.br/bitstream/123456789/30123/3/Sa\%c3\%badeMentalUso.pdf

MAIA, B. R., \& DIAS, P. C. (2020). Ansiedade, depressão e estresse em estudantes universitários: o impacto da COVID-19. Estud. psicol. (Campinas), Campinas, v. 37, 2020. Disponível em: https://www.scielo.br/pdf/estpsi/v37/1678-9865-estpsi-37-e200067.pdf

MONDARDO, A.H; PEDON, E.A. Estresse e desempenho acadêmico em estudantes universitários. Revista de Ciências Humanas, 2005. Disponível em: http://www.revistas.fw.uri.br/index.php/revistadech/article/viewFile/262/480

PEREIRA, M. D. et al. A pandemia de COVID-19, o isolamento social, consequências na saúde mental e estratégias de enfrentamento: uma revisão integrativa. Research, Society and Development, v. 9, n. 7, 2020. Disponível em: https://rsdjournal.org/index.php/rsd/article/view/4548/4043

REIS, C.F; MIRANDA, G.J; FREITAS, S.C Ansiedade e desempenho acadêmico: Um estudo com alunos de Ciências Contábeis. Advances in Scientific and Applied Accounting. São Paulo, v. 10, n.3, p. 319 - 333, 2017. Disponível em: http://asaa.anpcont.org.br/index.php/asaa/article/view/356/194

SANTOS, F. D.. Descoberta do desânimo de alunos em ambientes virtuais de ensino e aprendizagem: um modelo a partir da mineração de dados educacionais. 2016. Disponível em: https://www.lume.ufrgs.br/handle/10183/148320

VEIGA, N. H. et al. Teoria da adaptação e saúde do trabalhador em home office na pandemia de covid-19. Rev. baiana enferm., 2020. Disponível em: https://cienciasmedicasbiologicas.ufba.br/index.php/enfermagem/article/view/37636/23484 